\title{
CHANGES IN HUMIC ACID CONFORMATION DURING COAGULATION WITH FERRIC CHLORIDE: IMPLICATIONS FOR DRINKING WATER TREATMENT
}

J-M. Siéliéchi1,2, B.S. Lartiges ${ }^{*}$, G.J. Kayem ${ }^{2}$, S. Hupont ${ }^{3}$, C. Frochot $^{3}$,

J. Thieme ${ }^{4}$, J. Ghanbaja ${ }^{5}$, J.B. d'Espinose de la Caillerie ${ }^{6}$, O. Barrès ${ }^{1}$, R. Kamga ${ }^{2}$, P. Levitz ${ }^{7}$, L.J. Michot ${ }^{1}$

${ }^{1}$ Nancy University - LEM-ENSG/INPL-CNRS, Pôle de l'Eau 15 Avenue du Charmois BP 40, 54501 Vandoeuvre Cedex, France

2 University of Ngaoudere - ENSAI-IUT, P.O. Box 455, Cameroon.

${ }^{3}$ Nancy University - UMR 7630 CNRS-INPL-ENSIC, 1 rue Grandville, BP 451, 54500 Nancy, France

${ }^{4}$ Institute for X-Ray Physics, University Georgia Augusta, Geistrasse 11, D-37073

Göttingen, Germany

${ }^{6}$ ESPCI, 10 rue Vauquelin, 75231 Paris Cedex, France

${ }^{7}$ Ecole Polytechnique - LPMC-CNRS - 91128 Palaiseau Cedex, France

- corresponding author: bruno.lartiges@get.omp.eu 


\begin{abstract}
Electrophoretic mobility, pyrene fluorescence, surface tension measurements, Transmission Electron Microscopy on resin-embedded samples, and X-ray microscopy were combined to characterize the aggregates formed from humic colloids and hydrolyzed-Fe species under various conditions of $\mathrm{pH}$ and mixing. We show that, at low coagulant concentration, the anionic humic network is reorganized upon association with cationic coagulant species to yield more compact structures. In particular, spheroids about $80 \mathrm{~nm}$ in size are evidenced by X-ray microscopy at $\mathrm{pH} 6$ and 8 just below the optimal coagulant concentration. Such reorganization of humic colloids does not yield surface active species, and maintains negative functional groups on the outside of humic/hydrolyzed Fe complex. We also observe that the humic network remains unaffected by the association with coagulant species up to the restabilization concentration.

Upon increasing the coagulant concentration, restructuration becomes limited : indeed, the aggregation of humic acid with hydrolyzed-Fe species can be ascribed to a competition between humic network reconformation rate and collision rate of destabilized colloids. A decrease in stirring favors the shrinkage of humic/hydrolyzed Fe complexes, which then yields a lower sediment volume. Elemental analyses also reveal that the iron coagulant species are poorly hydrolyzed in the destabilization range. This suggests that destabilization mechanisms such as sweep-flocculation or adsorption onto a hydroxyde precipitate are not relevant to our case. A similar neutralization/complexation destabilization accompanied by a restructuration of flexible humic network is then proposed to occur in the range of pHs investigated.
\end{abstract}

Key words: Coagulation, humic substances, ferric chloride, X-ray microscopy, pyrene fluorescence. 


\section{INTRODUCTION}

Humic substances represent the dominant part of dissolved organic matter in freshwater supplies (Zumstein and Buffle, 1989). Their elimination upon drinking water treatment is mainly performed by coagulation with hydrolyzed metal species. Considerable attention has then been focused on this removal step as uncoagulated humic materials lead to severe problems in the following treatment stages. Indeed, membrane fouling, trihalomethanes formation during desinfection, or biological regrowth in the distribution network, have all been linked to the presence of residual humic substances in clarified water (e.g. Owen et al., 1995 ; Lin et al., 2000). Three main mechanisms are generally invoked to explain the removal of humic substances by coagulation: charge neutralization/complexation preferentially applies at acidic $\mathrm{pH}$ and finds experimental support from stoichiometric relationships between coagulant demand and dissolved organic matter concentration, and from suspension restabilization upon overdosing (e.g. Narkis and Rehbun, 1977). On the other hand, under conditions favoring metal hydroxide precipitation, physical ensmeshment and/or adsorption onto the freshly formed precipitate are assumed to play a major role in humic substances elimination (e.g. Bose and Reckow, 1998).

None of these destabilization mechanisms explicitly refers to the nature of humic material. Humic substances are commonly described as heterogeneous compounds containing both a large proportion of oxygen-substituted functional groups (essentially carboxylic and phenolic) that make them hydrophilic (Ritchie and Perdue, 2003), and seggregated aromatic and aliphatic moieties (Chien and Bleam, 1998) that give them surface active and hydrophobic binding properties (Chen and Schnitzer, 1978; Engebretson and von Wandruszka, 1994). Direct flow-field flow fractionation investigations of natural freshwaters suggest that humic colloids are about 1-2 nm in diameter (Lyvén et al., 2003; Baalousha and Lead, 2007), which concurs with previous characterizations of extracted humic material using Transmission Electron Microscopy (TEM), Atomic Force Microscopy (AFM), and Small-Angle X-ray and Neutron 
Scattering (Balnois et al., 1999; Wilkinson et al., 1999; Kawahigashi et al., 1995; Knöchel et al., 1997; Österberg et al., 1993). The size of humic substances is also known to depend on $\mathrm{pH}$ : a stretched configuration occurs at alkaline $\mathrm{pH}$ due to intramolecular electrostatic repulsions, whereas small humic aggregates can be formed below pH 5 (Lead et al., 2000; Plaschke et al. 1999). In addition, adsorption data and multivalent cations complexation experiments reveal changes in humic conformation upon interaction (Veermer et al. 1998; Wilkinson et al., 1999 ; Engebretson and von Wandruszka, 1998).

Modeling of their charge characteristics implies that humic substances are soft and porous structures (Duval et al., 2005). However, the detailed organization of humic nanocolloids remains a matter of debate: they have long been regarded as linear or slightly branched polymers that can coil or adopt an extended conformation according to solution properties (Ghosh and Schnitzer, 1980; Swift, 1999). On the other hand, recent Diffusion Ordered Spectroscopy (DOSY) and Size Exclusion Chromatography (SEC) suggest that humic colloids are supramolecular associations of small heterogeneous molecules that can be disrupted in the presence of organic acids (Simpson 2002, Piccolo, 2001; Conte and Piccolo, 1999).

Both concepts are consistent with a flexible humic structure. Yet, such an aspect is not taken into account in traditional coagulation mechanisms. As shown in recent electron energy loss spectroscopy and pyrene fluorescence experiments (Jung et al., 2005b; Kazpard et al., 2006), conformational rearrangements can also be evidenced during the coagulation of negatively charged humic colloids with cationic hydrolyzed metal species. In this paper, we investigate the coagulation behavior of Nyong river humic acid with ferric chloride. Nyong river is located in the African tropical rainforest, which allows to document the removal by coagulation of humic substances from the strongly coloured surface waters encountered in this area (Olivié-Lauquet et al., 2000). We examine the interplay between humic reorganization rate and colloid/hydrolyzed Fe species collision rate by varying the agitation conditions, the humic aggregates being 
characterized by pyrene fluorescence, electrophoretic mobility, TEM on resin embedded samples, and X-ray microscopy.

\section{MATERIALS AND METHODS}

Origin, extraction, and characterization of Nyong humic acid (NHA). The humic acid used in the present study was extracted from Nyong river sediment (Cameroon). The sampling site is located upstream Akomnyada drinking water treatment plant (SNEC Mbalmayo $3.51^{\circ} \mathrm{N}, 11.5^{\circ} \mathrm{E}$ ) in the tropical rain forest area. The natural $\mathrm{pH}$ of Nyong river water is about 5.8, and Dissolved Organic Carbon (DOC) is in the $20 \mathrm{mg} / \mathrm{L}$ range (Viers et al., 1997; Olivié-Lauquet et al., 2000). About $20 \mathrm{~kg}$ of sediments were collected from the bedload superficial layer of Nyong river at the end of the dry season (september 2003). The sediments were dried at room temperature $\left(30^{\circ} \mathrm{C}\right)$, and then sieved through a 2-mm screen. The separation and purification of humic acid fraction was based on Thurman and Malcom procedure (1981), adapted to yield the extract in a sodium form (Jung et al., 2005). Elemental analysis of NHA (Carlo Erba 1108 autoanalyser) indicated contents of $49.6 \%$ in $\mathrm{C}, 4.3 \%$ in $\mathrm{H}, 3.5 \%$ in $\mathrm{N}$, and $41.8 \%$ in $\mathrm{O}$. Potentiometric titration (Jung et al., 2005) reveals a total titratable charge of 2.97 $\mathrm{meq} / \mathrm{g}$.

Infrared analysis ( $1 \mathrm{mg}$ NHA mixed with $250 \mathrm{mg} \mathrm{KBr}$ ) was carried out with a Bruker IFS 55 spectrometer in transmission mode (200 scans collected at $2 \mathrm{~cm}^{-1}$ resolution in the $4000-400 \mathrm{~cm}^{-1}$ range). The main FTIR bands were assigned according to Baes and Bloom (1989). The spectrum (Fig. 1a) exhibits the main infrared bands usually reported for humic material and it closely resembles that of copropellic ooze from Mud Lake (Florida) described by Stevenson and Goh (1971).

The $\left\{{ }^{1} \mathrm{H}_{-}{ }^{13} \mathrm{C}\right\}$ CP/MAS spectrum was obtained with a Bruker ASX 500 instrument at $125.77 \mathrm{MHz}$, spinning at $10 \mathrm{kHz}$, with a $\pi / 2$ pulse of $8 \mathrm{~s}$, contact times of $1 \mathrm{~ms}$, recycle delays of $5 \mathrm{~s}$ and around 14000 transients ; line broadening procedure $(100 \mathrm{~Hz})$ was applied before Fourier transform, and the chemical shifts were quoted 
relative to TMS. CPMAS ${ }^{13} \mathrm{C}$ NMR spectra of humic substances are typically divided into four resonance ranges: alkyls (0-50 ppm), O-alkyls (50-110 ppm), aromatics (110160 ppm), and carbonyls (160-220 ppm) (e.g. Mahieu et al., 1999). Figure 1b shows that the NHA NMR spectrum is dominated by two well-resolved aliphatic peaks (27 and $47 \mathrm{ppm})$. It also exhibits two resonances at 73 and $103 \mathrm{ppm}$ that could indicate the presence of polysaccharides (Wilson et al. 1981). The aromatic region contains two significant resonances at 123 and $147 \mathrm{ppm}$, assigned to phenolic ring carbon and aromatic ring carbon, respectively. The major signal at $173 \mathrm{ppm}$ is assigned to carboxylic carbon, whereas the two weak resonances at 200 and 217 ppm are likely due to ketonic carbons. Even though CPMAS NMR results are not quantitative, the proportions of aliphatic and aromatic carbons contained in NHA are quite similar to that found in many freshwater humic substances (Wilson et al., 1981; Malcom, 1990; Wong et al., 2002; Peuravuori, 2005).

Preparation of reconstituted waters and aggregation procedure. Suspensions were obtained by dissolving $25 \mathrm{mg}$ of NHA in $1 \mathrm{~L}$ of deionised water (Millipore-MilliQ, 18.5 $\mathrm{M} \Omega / \mathrm{cm}$ ), thus yielding a dissolved organic carbon of $10 \mathrm{mg} / \mathrm{L}$. Sodium hydrogenocarbonate $\left(\mathrm{NaHCO}_{3} 4 \quad 10^{-3} \mathrm{~mol} / \mathrm{L}\right)$ was also added into the suspension to provide a carbonate alcalinity similar to that of natural river waters. Prior to coagulant injection, the $\mathrm{pH}$ of synthetic waters was adjusted to $\mathrm{pH} 6$ or 8 with dropwise addition of $0.1 \mathrm{M} \mathrm{HCl}$. The coagulant, a commercial ferric chloride kindly supplied by Groupe Arkema (France), corresponds to a $38 \%$ wt $\mathrm{FeCl}_{3}$ unhydrolyzed solution.

Coagulation tests were conducted at $25^{\circ} \mathrm{C}$ in $1 \mathrm{~L}$ reactors $(9 \mathrm{~cm}$ in diameter) fitted with 4 plexiglas baffles $(1.2 \times 15 \mathrm{~cm})$. Stirring was carried out with a rectangular paddle $(1.5 \times 5.5 \mathrm{~cm})$ located at one-third of the beaker height from the bottom. Two mixing procedures yielding the same overall energy input to the coagulated suspension, were used : (i) a rapid mix period for $3 \mathrm{~min}$ at $250 \mathrm{rpm}$ (mean velocity gradient $\mathrm{G}=452$ $\left.\mathrm{s}^{-1}\right)$ followed by slow stirring at $60 \mathrm{rpm}\left(\mathrm{G}=84 \mathrm{~s}^{-1}\right)$ for $30 \mathrm{~min}$, (ii) a continuous slow mixing at $60 \mathrm{rpm}$ for $46 \mathrm{~min}$. The coagulant was added under agitation as pure solution 
using a micro-pipette (Eppendorf) at a point just below the free surface of the suspension. At the end of mixing, the coagulated suspension was allowed to settle in graduated Imhoff cones. $50 \mathrm{~mL}$ of supernatant were withdrawn with a syringe from about $25 \mathrm{~mm}$ below the free surface, at $30 \mathrm{~min}$ and $24 \mathrm{~h}$ settling. Residual turbidity (Ratio XR Turbidimeter Hach), sediment volume, pH (Meter Lab PHM 210 Tacussel), conductivity (CD 810 Tacussel) were monitored at both sampling times, whereas electrophoretic mobility and surface tension measurements, pyrene fluorescence emission, and both TEM and X-ray microscopy observations, were carried out on the 24h settled suspensions.

Characterization of NHA aggregates. Hydrophobic/hydrophilic properties of coagulated NHA were characterized by measuring surface tension, electrophoretic mobility, and the intensity ratio of the first/third band in pyrene fluorescence emission spectrum.

The fluorescence emission spectra of pyrene were recorded at $25 \pm 0.1^{\circ} \mathrm{C}$ on a Fluorolog-3 spectrofluorometer (SPEX, Jobin Yvon), using $2 \mathrm{~nm}$ slits for the excitation and emission monochromators, $1 \mathrm{~nm}$ increment, and an integration time of $1 \mathrm{~s}$. Pyrene (99\% - Fluka) was first dissolved in ethanol (99.5\% spectrophotometric grade Aldrich) to prepare a $10^{-3} \mathrm{~mol} / \mathrm{L}$ stock solution. Aliquots of $0.6 \mathrm{~mL}$ were then added to the NHA suspensions to yield a $610^{-7} \mathrm{~mol} / \mathrm{L}$ pyrene concentration. The volumetric content of ethanol introduced in the samples is less than $0.6 \%$ and does not influence the solubility of pyrene in samples. Normal jar test procedures were then carried out.

Prior to fluorescence measurements, coagulated NHA-pyrene samples were homogeneized by gentle over-hand shaking. Pyrene excitation wavelength was set at $332 \mathrm{~nm}$ and the emission was collected between 350 and $450 \mathrm{~nm}$. The polarity sensitive ratio $\mathrm{I}_{1} / \mathrm{I}_{3}$ was calculated from the emission intensities at $372 \mathrm{~nm}\left(\mathrm{I}_{1}\right)$ and $383 \mathrm{~nm}\left(\mathrm{I}_{3}\right)$. The measurements were made in duplicate, and the corresponding average relative intensity ratio is presented. In order to compare the fluorescence intensities of samples and to avoid equipment baseline time drift, the fluorescence was normalized with a 0.16 
$\mathrm{mg} / \mathrm{L}$ fluorescein solution buffered at $\mathrm{pH} 10$, using an excitation wavelength of $488 \mathrm{~nm}$ with emission recorded from 500 to $550 \mathrm{~nm}$.

Surface tension measurements were performed at $23 \pm 0.5^{\circ} \mathrm{C}$ using a KSV Sigma 70 tensiometer equipped with a Noüy ring. Prior to each measurement, the Noüy ring was carefully cleaned and heated with a bunsen burner flame to avoid contamination from adsorbed NHA. A series of 10 measurements was carried out at each coagulant concentration, the average surface tension being calculated from Sigma 70 software. The standard error between the measurements was within $2 \%$.

The electrophoretic mobility of unsettled aggregates was measured with a Zetaphoremeter III (Sephy, France) equipped with a CCD camera. Prior to the measurements, the supernatant of the settled suspensions was centrifuged at $2500 \mathrm{rpm}$ for 10 minutes in a lab-centrifuge (Eppendorf 5804) to increase the particle concentration. The centrifugate was then re-suspended in $50 \mathrm{ml}$ of original supernatant before being pumped into the electrophoretic cell. This procedure may induce a slight compaction of the floc structure. However, such a rearrangement occurs at a much larger scale than that associated with the diffuse double layer. The velocity of particles located at the stationary layer was directly computed from a video analysis obtained at fixed time intervals under an $80 \mathrm{mV}$ applied voltage.

Imaging of NHA aggregates Transmission Electron Microscopy (TEM) and X-ray Microscopy were used to image NHA coagulated structures. TEM was carried out with a Phillips CM 20 equipped with energy dispersive X-ray spectrometer, from ultrathin slices obtained from resin-embedded samples. Resin-embedding was carried out following a classical procedure (Lartiges et al., 2001) : coagulated samples were first chemically fixed with $2 \%$ osmium tetroxide for $1 \mathrm{~h}$, excess fixative being removed by washing with centrifuged treated water. Stepwise acetone dehydration (5 min at 10, 20, 40 , and $60 \%, 15 \mathrm{~min}$ at $80 \%, 2 \times 15 \mathrm{~min}$ at $95 \%$, and $3 \times 20 \mathrm{~min}$ at $100 \%$ acetone) was then conducted. Finally, acetone was exchanged with a graded series of epoxy resin monomers (Kit Embed 812, Euromedex), and the resin-impregnated samples were 
polymerized in molds at $60^{\circ} \mathrm{C}$ for $12 \mathrm{~h}$. Ultrathin sections $(\sim 1000 \AA)$ of resin embedded samples were cut using an ultramicrotome and a diamond knife (Reichert OM U2), and placed on carbon-coated copper grids.

X-ray microscopy (XRM) was performed at Bessy II using the transmission Xray microscope developed by the Institute for X-ray physics (University of Göttingen) (Wiesemann et al., 2000). An X-ray wavelength just above oxygen K-absorption edge $(\lambda=2.34 \mathrm{~nm})$ was used. In that case, organic matter and iron hydrolyzed species show a much higher absorption than water, thus providing a natural contrast for the coagulated humic material in aqueous media. Using the Fresnel condenser and micro zone plate of the set-up, and $\lambda=2.34 \mathrm{~nm}$, the resolution attained with the X-ray microscope was about $20 \mathrm{~nm}$. Microliters of coagulated sediment were placed between polymer membranes in an object chamber built for XRM (Guttmann et al., 1992). The sample thickness is then below a few microns which limits the absorption of X-rays by the water layer. Exposure times for obtaining an image are in the range of a few seconds. No radiation damage was observed in our samples. X-ray images were divided with the corresponding background image, and the grey level was then re-calibrated between 0 and 255 .

\section{RESULTS AND DISCUSSION}

Destabilization of NHA with ferric chloride. As illustrated in figure 2, a similar coagulation behavior is observed at $\mathrm{pH} 6$ and 8 for an initial mixing agitation of 250 rpm. The residual turbidity increases at low iron dosages to reach a maximum, and then it steeply decreases with further coagulant addition (fig. 2a-b). The point where the extrapolated steep portion of the turbidity curve intersects the $\mathrm{x}$-axis is chosen as the optimum coagulant concentration (OCC). Above OCC, the residual turbidity remains low until the restabilization of the suspension is induced by excess coagulant. On the other hand, the sediment volume rapidly builds up just before OCC as settleable 
aggregates begin to form, it levels off in the destabilization domain, and it sharply diminishes around the restabilization concentration $(\mathrm{RC})$.

At both investigated $\mathrm{pHs}$, the $\mathrm{pH}$ gradually decreases with iron addition from the initial suspension $\mathrm{pH}$ to a value close to 5, and it then drops to about $\mathrm{pH} 3.5$ as ferric chloride hydrolysis exceeds the buffer capacity of the solution (fig. 2c-d). Conductivity measurements reveal three domains : at low coagulant concentrations, the conductivity slightly increases ; just before OCC, a stronger increase in conductivity is observed. From OCC, the conductivity re-increases with a lesser slope and it exhibits another sharp increase around the restabilisation concentration. The two successive strong increases in conductivity can be attributed respectively, to a release in sodium and calcium ions from NHA functional groups upon association with coagulant species (Jung et al., 2005b), and to the formation of soluble iron species at the restabilisation concentration (El Samrani et al., 2004).

The jar-test results obtained at $\mathrm{pH} 8$ are characterized by (i) an increase in $\mathrm{OCC}$, (ii) a wider range of optimal dosing, and (iii) a higher sediment volume in the destabilization domain. Thus, optimal coagulant concentrations of $2.410^{-4}$ and $5.910^{-4}$ $\mathrm{mol} / \mathrm{L}$ are found at $\mathrm{pH} 6$ and 8 , respectively. This corresponds to $\mathrm{Fe} / \mathrm{C}$ mass ratios of 1.1 and 2.75 (i.e. Fe/C elemental ratios of 0.29 and 0.72 ) at $\mathrm{pHs} 6$ and 8, respectively. Such values fall in the range usually reported in the literature for the aggregation of humic substances with iron-based coagulants (e.g. Lefebvre and Legube, 1990 ; Jung et al., 2005b). The higher coagulant demand and the larger destabilization domain at $\mathrm{pH} 8$ can be attributed to (i) an increased deprotonation of NHA functional groups, (ii) a change in humic conformation that makes more binding sites available for coagulant species, and (iii) a smaller charge of Fe-hydrolyzed Fe-species. Interestingly, even though the coagulation $\mathrm{pH}$ is not constant, the ratio of restabilization concentration to optimal dosage remains equal to 2.45 at both $\mathrm{pHs}$.

Several parameters such as number and size of coagulant species, conformation of humic colloids, and aggregate structure, may be involved in the variation of settled volume with $\mathrm{pH}$. As the sediment volume is almost constant in the range of optimal 
dosing, the number of coagulant species, and the difference in number of those between pH 6 and 8, can not explain the magnitude of settled volume. Furthermore, recent EXAFS investigations have shown that Fe-hydrolyzed species are poorly polymerized in presence of natural organic matter around OCC even at basic pH (Vilgé-Ritter et al., 1999 ; El Samrani et al., 2004). Therefore, in our case, the size of coagulant species should not significantly influence the aggregate volume. The role played by humic conformation in determining the sediment volume is more obvious. Indeed, it has long been known that, at basic $\mathrm{pH}$, the increased deprotonation of humic colloids, either polymeric or self-assembly, yields stretched or swelled structures with greater steric hindrance (e.g. Ghosh and Schnitzer, 1980). Such an effect may be enhanced by a change in aggregate structure as aggregates with lower fractal dimension were reported at basic $\mathrm{pH}$ in the case of NOM coagulated with ferric chloride (Vilgé-Ritter et al., 1999).

The effect of mixing conditions on the jar-tests carried out at $\mathrm{pH} 6$ and 8 is shown in figure 3 . The residual turbidity curves are almost superimposed at both pHs, which is in accordance with previous results indicating that agitation does not significantly influence coagulant demand (e.g. Lefebvre and Legube, 1990 and references herein). Nevertheless, a slightly higher restabilization concentration can be noted when the initial mixing intensity is increased. The settled volumes are also distinctly different in the range of optimal dosing with, surprisingly, a drastic decrease in sediment volume under low mixing intensity. In that case, restructuring into a more compact aggregate structure, that usually occurs at high mixing speed (e.g. Spicer et al., 1998), can not be invoked to account for the formation of a smaller sediment volume. Instead, it can be explained by a reorganization of anionic humic colloids upon association with positively charged coagulant species, a decrease in collision rate allowing a more effective reconformation into denser aggregates, and hence a decrease in settled volume. Therefore, the size of the coagulated humic colloid would be a predominent factor in determining sediment volume. 


\section{Electrophoretic mobility, pyrene fluorescence, and surface activity of NHA}

coagulated suspensions. Figures $4 \mathrm{a}$ and $4 \mathrm{~b}$ illustrate the influence of ferric chloride concentration on NHA aggregates electrophoretic mobility and $I_{1} / I_{3}$ pyrene fluorescence intensity ratio at pHs 6 and 8 (Initial mixing intensity of $250 \mathrm{rpm}$ ). At both $\mathrm{pHs}$, the electrophoretic mobility of aggregates is negative up to the optimal dosage even though NHA coagulated well at OCC. Such behavior is consistent with a rearrangement of anionic humic colloids around positive coagulant species that maintains net negative charges on the outside of the humic/hydrolyzed-Fe complex. However, it could also result from the heteroaggregation of oppositely charged humics and hydrolyzed-Fe species without humic reorganization. At higher coagulant dosages, the electrophoretic mobility gradually increases and charge reversal is observed before the restabilization concentration at $\mathrm{pH} 6$, and at $\mathrm{RC}$ at $\mathrm{pH} 8$. As can be seen in figures 1 and 2, the charge reversal of NHA aggregates induces a slight increase in sediment volume.

The pyrene intensity ratio $\mathrm{I}_{1} / \mathrm{I}_{3}$ provides a polarity sensor that has been used to probe the micellar properties of humic acid systems (Engebretson and von Wandruszka, 1994 ; 1998). Indeed, pyrene is much more soluble in apolar solvents than in water, and it migrates from the aqueous phase into hydrophobic microenvironments with remarkable changes in its fluorescence emission spectrum (Kalyanasundaram and Thomas, 1977). Thus, $I_{1} / I_{3}$ is about 1.9 in pure water, whereas it is much lower in apolar phases (e.g. $\mathrm{I}_{1} / \mathrm{I}_{3} \sim 0.6$ in hexane). A similar pattern is obtained for the evolution of pyrene intensity ratio as a function of iron concentration at both pHs 6 and 8: at low coagulant dosages, $\mathrm{I}_{1} / \mathrm{I}_{3}$ decreases from an initial value slightly below 1.65 , to a minimum of about 1.56 at $\mathrm{pH} 6$, and of 1.45 at $\mathrm{pH} 8$. It then sharply rises just before OCC to reach $I_{1} / I_{3}$ values slightly higher than those of the original NHA suspension. From OCC, the pyrene intensity ratio gradually diminishes until the restabilization concentration; it then rapidly drops to more hydrophobic values with further increase in coagulant dosage. 
The initial decrease in pyrene intensity ratio indicates the formation of a relatively hydrophobic microenvironment around the fluoroprobe. As both pyrene associated with coagulated NHA and pyrene remaining in water contribute to the recorded value of $\mathrm{I}_{1} / \mathrm{I}_{3}$, the solubilization within a more hydrophobic environment may be explained by (i) structural changes of humic colloid upon coagulation which enhance the hydrophobicity of pyrene sorption sites, and/or (ii) an increased partition of the fluoroprobe into these newly created hydrophobic regions. A reorganization of humic network is indeed expected with the elimination of humic negative charges by the cationic coagulant species : neutralization likely favors hydrophobic interactions, which may result in an overall shrinkage of the organic colloid with release of hydration water, and thus lead to the formation of hydrophobic microenvironments referred to as intramolecular humic pseudomicelles in previous reports (Engebretson and van Wandruszka, $1994 ; 1998)$.

Further coagulant addition reverts the evolution of $\mathrm{I}_{1} / \mathrm{I}_{3}$, the most hydrophilic environment being observed at OCC. This phenomenon, which may appear at first as a demicellization process, can in fact be ascribed to the competition between intra-humic reorganization upon association with hydrolyzed-Fe species and inter-humic clustering, the reconformation of humic network being hindered within the aggregate. The influence of mixing conditions on pyrene intensity ratio at $\mathrm{pH} 6$ supports such an interpretation (fig. $5 b$ ) : the minimum value in $\mathrm{I}_{1} / \mathrm{I}_{3}$ indicating the maximum shrinking of humic colloid, is shifted towards higher coagulant concentrations at low mixing intensity. Moreover, the pyrene intensity ratio in the optimal dosing range increases with agitation or collision rate which is consistent with a limited reconformation. However, at $\mathrm{pH} 8$, the effect of mixing intensity on $\mathrm{I}_{1} / \mathrm{I}_{3}$ appears to be negligible (fig. 5d) whereas a small decrease in sediment volume was noted at low agitation. Likewise, the electrophoretic mobility curves are almost superimposed for both mixing sequences, and do not reveal any significant influence of mixing conditions (fig. 5a and 5c).

The drop in pyrene intensity ratio at restabilization concentration is not straightforward to explain. On the one hand, the binding of an excess coagulant species 
onto the humic network implies electrostatic repulsions and swelling of humic structure, thus providing access to supplementary hydrophobic binding sites of pyrene. On the other hand, above $\mathrm{RC}$, the $\mathrm{pH}$ is lowered to 3.5 and the protonation of carboxylic functional groups may enhance the formation of hydrophobic microenvironments, and hence, the solubilization of pyrene fluroprobe.

Humic substances are well-known surface-active compounds (e.g. Chen and Schnitzer, 1978). As shown in figure 6a, humic colloids extracted from Nyong river sediments significantly lower the surface tension $\gamma:$ the $\gamma$-NHA concentration plot presents an initial convex decrease of surface tension which is reminiscent of that typically observed for amphilic copolymers (e.g. Garnier and Laschewsky, 2006). A plateau at $64 \mathrm{mN} / \mathrm{m}$ is then obtained at $\mathrm{pH} 6$ from a NHA concentration of $0.3 \mathrm{~g} / \mathrm{L}$, whereas surface tension decreases more continously at $\mathrm{pH} 8$ to a $\gamma$ value slightly below $60 \mathrm{mN} / \mathrm{M}$ at $1 \mathrm{~g} / \mathrm{L}$. Such values are comparable with those usually reported for humic substances (Chen and Schnitzer, 1978 ; Terashima et al., 2004).

Upon coagulation, the surface tension of NHA suspensions remains almost constant at low coagulant dosages, it exibits a sharp increase just before OCC, and then a slower continuous increase to reach a similar value of $71.5 \mathrm{mN} / \mathrm{m}$ at both pHs 6 and 8 in the restabilization domain (Fig. 6b). Therefore, even though pyrene fluorescence results indicated that the neutralization of NHA with hydrolyzed-Fe species induces a reorganization of humic network, such restructuring does not lead to the formation of surface active entities. Comparison with the conductivity vs iron concentration curve (fig. 2), reveals that the increase in surface tension can simply be related to the change in solution ionic strength with coagulant addition.

TEM and X-ray microscopy observations of coagulated NHA. TEM examination of resin-embedded coagulated sediments reveals obvious changes in the organization of humic aggregates as a function of coagulant concentration (figure 7). At the onset of sediment formation $\left([\mathrm{Fe}]=2.310^{-4} \mathrm{~mol} / \mathrm{L}-\mathrm{pH}=6\right.$ - Agitation sequence $60 / 60$ ), the coagulated NHA is characterized by cloudy structures containing dispersed 
8-15 nm electron-dense areas. At optimal dosage, the humic aggregates become more granulous with electron-dense areas of slightly smaller size. Finally, just below the restabilization concentration $\left([\mathrm{Fe}]=4.5610^{-4} \mathrm{~mol} / \mathrm{L}\right)$, nanocolloids of about $3 \mathrm{~nm}$ in diameter and a few $30 \mathrm{~nm}$ long nanorods can be recognized within the coagulated sediment. A similar pattern with smaller electron-dense areas and larger nanorods, is obtained with a $250 \mathrm{rpm}$ initial agitation (fig. 6d-f).

At first sight, the TEM observations substantiate the pyrene fluorescence results : the electron-dense areas detected below and around OCC imply an increased compacity that can result from a reconformation of humic colloids upon binding of coagulant species. On the other hand, close to the restabilization concentration, the homogeneous and diffuse aspect of humic aggregates is consistent with an expanded structure that can be associated with intraparticle electrostatic repulsions. However, the $3 \mathrm{~nm}$ colloids and the $30 \mathrm{~nm}$ nanorods also fell in the size range of ferric chloride hydrolysis products (e.g. Murphy et al., 1976; Combes et al., 1989). The $10 \mathrm{~nm}$ spot size used to record EDX spectra does not allow to discriminate the chemical composition of electron-dense areas and nanorods. Nevertheless, as osmium tetroxide reacts with carbon double bonds of organic colloids, the Fe/Os elemental ratio can be used to assess the relative compacity of humic aggregates as a function of mixing conditions. Table 1 shows that larger Fe/Os ratios, and hence lower aggregate densities, are calculated for the $250 \mathrm{rpm}$ initial agitation, which is in agreement with the smaller electron-dense areas and higher sediment volume noted at this mixing speed. Therefore, the $3 \mathrm{~nm}$ colloids likely identify the original humic colloids, and the nanorods could correspond to chains of those $3 \mathrm{~nm}$ subunits. This also implies that, up to the restabilization concentration, the overall integrity of humic network is maintained during coagulation.

Elemental microanalyses of humic aggregates also reveal that $\mathrm{Fe} / \mathrm{Cl}$ elemental ratio changes with coagulant concentration and initial mixing speed (Table 1). EXAFS investigation of ferric chloride hydrolysis showed that $\mathrm{Cl}^{-}$ions are clearly detected in the vicinity of Fe-hydrolyzed species, with $\mathrm{Fe} / \mathrm{Cl}$ close to 1 for $\mathrm{OH} / \mathrm{Fe}$ ratio equal to 2 
(Combes et al., 1989; Bottero et al., 1994). As fully hydrolyzed ferric chloride yields the formation of $\beta-\mathrm{FeOOH}$ akaganeite with a $12 \% \mathrm{wt}$ chloride content or $\mathrm{Fe} / \mathrm{Cl}=6.4$ (Post et al., 2003), $\mathrm{Fe} / \mathrm{Cl}$ values between 1 and 2.3 indicate the presence of poorly polymerized Fe-species within the humic aggregates. This agrees with previous EXAFS and EELS experiments showing that iron hydrolysis is hindered to the oligomeric stage in the presence of natural organic matter (Vilgé-Ritter et al., 1999 ; Jung et al., 2005b). Furthermore, the influence of mixing conditions on $\mathrm{Fe} / \mathrm{Cl}$ atomic ratio suggests that $\mathrm{Fe}$ hydrolysis is stopped once the coagulant species interact with the functional groups of humic colloids, a higher collision rate thus yielding a lower $\mathrm{Fe} / \mathrm{Cl}$ value.

Figure 8 compares the XRM images of (i) NHA coagulated at $\mathrm{pH} 2$ with the addition of $\mathrm{HCl} 0.5 \mathrm{M}$, (ii) humic aggregates obtained at $\mathrm{pH} 6$ and 8 with various coagulant concentrations (initial mixing speed of $250 \mathrm{rpm}$ ), (iii) a precipitate of ferric chloride at an initial $\mathrm{pH}$ of 8 . Unlike TEM, X-ray microscopy provides images of colloidal particles directly in aqueous suspension, and thus avoids the potential artifacts caused by the numerous preparation steps associated with resin-embedding. It is then very significant that the aspect of coagulated NHA in XRM images follows a similar pattern as that inferred from electron micrographs as a function of coagulant concentration. At pH 6 and below OCC, well-delimited clusters and aggregates of polydisperse dark spheroids, 30 to $120 \mathrm{~nm}$ in diameter, can be observed (fig. 8b-c). Around OCC, a few aggregates of dark spheroids remain sporadically distributed within a slightly granulated humic network (fig. 8d), whereas at still higher dosages, the coagulated NHA forms a thick inhomogeneous and cloudy structure. On the other hand, at $\mathrm{pH} 8$, the coagulated humic network seems both finer and denser below OCC (fig. 8f), whereas larger and more regular spheroids appear scattered in a slightly granular matrix around optimal dosage (fig. 8g). Above OCC, the granulated texture of humic aggregates becomes finer with coagulant concentration (fig. 8g-h), not reaching the homogeneous aspect of ferric chloride precipitate (fig. 8j). No XRM images of iron coagulated NHA display the diffuse netlike structure obtained at pH 2 (fig. 8a). 
Previous X-ray microscopy investigations of the interaction of humic substances with complexing cations or cationic detergents revealed similar features, although not in the sequence described above. A variety of netlike structures were observed with both soil and aquatic humic substances in presence of millimolar concentrations of $\mathrm{Cu}^{2+}$ or $\mathrm{Fe}^{3+}$ (Myneni et al., 1999 ; Thieme et al., 2002 ; Pranzas et al., 2003). Clusters of irregular spheroids, about $300 \mathrm{~nm}$ in size, were found by Myneni after adding $10^{-3} \mathrm{M}$ $\mathrm{Fe}^{3+}$ to $100 \mathrm{mg} / \mathrm{L}$ fluvial fulvic acid at pH 4 (Myneni et al., 1999), whereas Thieme and Niemeyer (1998) obtained dispersed spheres in the 200-600 $\mathrm{nm}$ size range, full or hollow, upon coagulation of a soil humic acid with various concentrations of cationic detergents. Ring-shaped structures, 20 to $70 \mathrm{~nm}$ in size, were also described at the mica surface using atomic force microscopy in fluid tapping-mode (Maurice and NamjesnikDejanovic, 1999 ; Plaschke et al., 1999). All these humic assemblies show two common characteristics: (i) their size is about two orders of magnitude larger than the elementary size of humic colloids, (ii) their shape, spheroid or toroid, suggests a minimization of surface energy. In our case, the dark spheroids are abundant just before OCC in a coagulant concentration range where $I_{1} / I_{3}$ values indicate a relatively hydrophobic environment of pyrene fluoroprobe. Therefore, such humic assemblies likely result from hydrophobic interactions between neutralized humic colloids that may partially merge upon association.

\section{CONCLUSION}

A schematic model can then be proposed for the aggregation of NHA with hydrolyzed Fe species (Fig. 9). As no consensus has been reached regarding the organization of humic substances, we simply assume that NHA can be depicted as a flexible low density network of hydrophobic and hydrophilic moieties. Such nanocolloids change conformation according to their ionization state, can be built either from amphiphilic polymers or assemblies of small molecules, and are then in accordance with previous models of the secondary structure of humic substances 
(Ghosh and Schnitzer, 1980 ; Piccolo 2001 ; Duval et al., 2005). The formation of NHA aggregates is then controlled by the number of coagulant species and two dynamics aspects: (i) the reconformation of humic network, and (ii) the collision rate of destabilized particles. An overall shrinkage of anionic humic network is indeed expected upon binding of cationic coagulant species, which promotes the formation of intra- and inter-particle hydrophobic domains according to the extent of neutralization. This suggests that, in addition to coagulant species, hydrophobic moieties participate to floc build-up. The rearrangement of humic network is necessarily restricted by the attachment of supplementary destabilized organic colloids, and hence by an increase in mixing intensity. Therefore, the interplay between reconformation and collision rates determines the variations in sediment volume in the range of optimal dosing.

The classical aggregation mechanisms proposed in the literature to explain the coagulation of humic substances include charge neutralization/precipitation at acid $\mathrm{pH}$, and adsorption and/or sweep-flocculation in an hydroxide precipitate at alkaline $\mathrm{pH}$. Our work suggests that a similar charge neutralization/complexation with poorly hydrolyzed-Fe species occurs at boths pHs. In that case, the increase in OCC would essentially result from an opening of the deprotononated humic network at alkaline $\mathrm{pH}$, thus increasing the number of carboxylic groups available for aggregation. This work does not settle the issue regarding the secondary structure of humic substances. However, it should be noted that Fe-hydrolyzed species are known to strongly interact with NOM carboxylic groups, and that the humic network remains unaffected even in the overdosage range at acid $\mathrm{pH}$ with highly charged coagulant species. As most features of Nyong river humic acid are similar to freshwater humic substances, the aggregation model described above should be general.

\section{ACKNOWLEDGMENT}

We thank the French embassy in Cameroon for partial funding of this work. 


\section{REFERENCES}

Baalousha M. and Lead J.R. (2007) Characterization of natural aquatic colloids $(<5 \mathrm{~nm})$ by flow-field flow fractionation and atomic force microscopy. Env. Sci. Technol. 41(4), 1111-1117.

Baes A.U. and Bloom P.R. (1989) Diffuse reflectance and transmission Fourier transform infrared (DRIFT) spectroscopy of humic and fulvic acids. Soil Sci. Soc. Am. J. 53, 695700.

Balnois E., Wilkinson K.J., Lead J.R., and Buffle J. (1999) Atomic force microscopy of humic substances: effects of $\mathrm{pH}$ and ionic strength. Environ. Sci. Technol. 33, 39113917.

Bose P. and Reckhow D.A. (1998) Adsorption of natural organic matter on preformed aluminum hydroxide flocs. J. Environ. Eng. 124, 803-811.

Bottero J-Y., Manceau A., Villieras F., Tchoubar D. (1994) Structure and mechanisms of formation of $\mathrm{FeOOH}(\mathrm{Cl})$ polymers. Langmuir 10, 316-319.

Chen Y. and Schnitzer M. (1978) The surface tension of aqueous solutions of soil humic substances. Soil Science 125, 7-15.

Chien Y.-Y. and Bleam W.F. (1998) Two-dimensional NOESY nuclear magnetic resonance study of $\mathrm{pH}$-dependent changes in humic acid conformation in aqueous solution. Environ. Sci. Technol. 32, 3653-3658.

Combes J.M., Manceau A., Calas G., Bottero J-Y. (1989) Formation of ferric oxides from aqueous solutions: a polyhedral approach by X-ray absorption spectroscopy: I. Hydrolysis and formation of ferric gels. Geochim. Cosmochim. Acta 53, 483-594.

Conte P. and Piccolo A. (1999) Conformational arrangement of dissolved humic substances. Influence of solution composition on association of humic molecules. Environ. Sci. Technol. 33, 1682-1690.

Duval J.F.L., Wilkinson K.J., van Leeuwen H.P., Buffle J. (2005) Humic substances are soft and permeable: evidence from their electrophoretic mobilities. Environ. Sci. Technol. 39, 6435-6445.

El Samrani, A.G., Lartiges, B.S., Montargès-Pelletier, E., Kazpard, V., Barrès, O., Ghanbaja, J. (2004) Clarification of municipal sewage with ferric chloride : the nature of coagulant species. Wat. Res. 38, 756-768.

Engebretson R.R. and von Wandruszka R. (1994) Microorganization in dissolved humic acids. Environ. Sci. Technol. 28, 1934-1941. 
Engebretson R.R. and von Wandruszka R. (1998) Kinetic aspects of cation-induced aggregation in aqueous humic acids. Environ. Sci. Technol. 32, 488-493.

Garnier S. and Laschewsky A. (2006) New amphiphilic diblock copolymers : surfactant properties and solubilization in their micelles. Langmuir, 22, 4044-4053.

Ghosh K. and Schnitzer M. (1980) Macromolecular structures of humic substances. Soil Sci. 129, 266-276.

Guttmann, P., Schneider G., Thieme J., David C., Diehl M., Medenwaldt R., Niemann B., Rudolph D., Schmahl G. (1992) SPIE The International Society for Optical Engineering - Proceedings, San Diego 1741, 53-61.

Jung, A.-V., Frochot, C., Parant, S., Lartiges, B.S., Selve, C., Viriot, M.-L., Bersillon, J.-L. (2005) Synthesis of amino-phenolic humic-like substances and comparison with natural aquatic humic acids: A multi-analytical techniques approach. Org. Geochem. 36(9), 1252-1271.

Jung, A.-V., Chanudet, V., Ghanbaja, J., Lartiges, B.S., Bersillon, J.-L. (2005b) Coagulation of humic substances and dissolved organic matter with a ferric salt : An electron energy loss spectroscopy investigation. Wat. Res. 39, 3849-3862.

Kalyanasundaram K. and Thomas J.K.J. (1977) Environmental effects on vibronic band intensities in pyrene monomer fluorescence and their application in studies of micellar systems. J. Am. Chem. Soc. 99(7), 2039-2044.

Kazpard V., Lartiges B.S., Frochot C., d'Espinose de la Caillerie J.B., Viriot M.L., Portal J.M., Görner T., Bersillon J.L. (2006) Fate of coagulant species and conformational effects during the aggregation of a model of a humic substance with $\mathrm{Al}_{13}$ polycations. Wat. Res. 40, 1965-1974.

Kawashigashi M., Fujitake N., Azuma J., Takahashi T., Jajiwara K., Urukawa H. (1995) The shape of humic acid in solution as observed by small-angle X-ray scattering. Soil. Sci. Plant Nutr. 41(2), 363-366.

Knöchel A., Pranzas K., Stuhrmann H., Willumeit R. (1997) Structural analysis of refractory organic substances by small-angle neutron scattering. Physica B234-236, 292-294.

Lartiges, B.S., Deneux-Mustin, S., Villemin, G., Mustin, C., Barrès, O., Chamerois, M., Gerard, B., Babut, M. (2001) Composition, structure and size distribution of suspended particulates from the Rhine river. Wat. Res. 35(3), 808-816. 
Lead J.R., Wilkinson K.J., Starchev K., Canonica S., Buffle J. (2000) Determination of diffusion coefficients of humic substances by fluorescence correlation spectroscopy: Role of solution conditions. Environ. Sci. Technol. 34, 1365-1369.

Lefebvre, E. and Legube, B. (1990) Iron (III) coagulation of humic substances extracted from surface waters : effect of $\mathrm{pH}$ and humic substances concentration. Wat. Res. 24(5), 591-606.

Lin C.F., Lin T.Y., and Hao O.J. (2000) Effects of humic substance characteristics on UF performance. Wat. Res. 34, 1097-1106

Lyvén B. Hassellöv, Turner D.R., Haraldsson C., Andersson K. (2003) Competition between iron- and carbon-based colloidal carriers for trace metals in a freshwater assessed using flow field-flow fractionation coupled to ICPMS. Geochim. Cosmochim. Acta 67(20), 3791-3802.

Malcom R.L. (1990) The uniqueness of humic substances in each soil, stream, and marine environments. Anal. Chim. Acta 232, 19-30.

Mahieu N., Powlson D.S., Randall E.W. (1999) Statistical analysis of published carbon-13 CP-MAS NMR spectra of soil organic matter. Soil Sci. Soc. Am. J. 63, 307-319.

Maurice, P.M. and Namjesnik-Dejanovic (1999) Aggregate structures of sorbed humic substances observed in aqueous solutions. Environ. Sci. Technol. 33(9), 1538-1541.

Murphy P.J., Posner A.M., Quirk J.P. (1976) Characterization of partially neutralized ferric chloride solutions. J. Colloid Interface Sci. 56(2), 284-297.

Myneni, S.C.B, Brown, J.T., Martinez, G.A., Meyer-Ilse, W. (1999) Imaging of humic substance macromolecular structures in water and soils. Science, 286, 1335-1337.

Narkis N. and Rebhun M. (1977) Stoichiometry relationship between humic and fulvic acids and flocculants. J.AWWA 69, 325-328.

Olivié-Lauqet G., Allard T., Bertaux J., Muller J-P. (2000) Crystal chemistry of suspended matter in a tropical hydrosystem, Nyong basin (Cameroon, Africa). Chem. Geol. 170, 113-131.

Österberg R., Lindqvist I., Mortensen K. (1993) Particle size of humic acid. Soil Sci. Soc. Am. J. 57, 283-285.

Owen D.M., Amy G.L., Chowdhury Z.K., Paode R., McCoy G., Viscosil K. (1995) NOM characterization and treatability. J. AWWA 87, 46-63.

Peuravuori J. (2005) NMR spectroscopy study of freshwater humic material in light of supramolecular assembly. Environ. Sci. Technol. 39, 5541-5549. 
Piccolo A. (2001) The supramolecular structure of humic substances. Soil Sci. 166(11), 810-832.

Plaschke, M., Römer, J., Klenze, R., Kim, J.I. (1999) In situ AFM study of sorbed humic acid colloids at different pH. Colloids Surf. A. Physicochem. Eng. Aspects 160, 269279.

Post J.E., Heaney P.J., von Dreele R.B., Hanson J.C. (2003) Neutron and temperatureresolved synchrotron X-ray powder diffraction study of akaganéite. Am. Mineral. 88, $782-788$.

Pranzas, P.K., Willumeit, R., Gehrke, R., Thieme, J., Knöchel, A. (2003) Characterization of structure and aggregation processes of aquatic humic substances using small-angle scattering and X-ray microscopy. Anal. Bioanal. Chem. 376, 618-625.

Ritchie J.D. and Perdue M.E. (2003) Proton-binding study of standard and reference fulvic acids, humic acids, and natural organic matter. Geochim. Cosmochim. Acta 67, 85-96.

Simpson A.J. (2002) Determining the molecular weight, aggregation, structures and interactions of natural organic matter using diffusion ordered spectroscopy. Magn. Reson. Chem. 40, S72-S82.

Spicer P.T., Pratsinis S.E., Raper J.A., Amal R., Bushell G., Meesters G. (1998) Effect of shear schedule on particle size, density, and structure during flocculation in stirred tanks. Powder Technol. 97, 26-34.

Stevenson F.J., and Goh K.M. (1971) Infrared spectra of humic acids and related substances. Geochim. Cosmochim Acta 35, 471-483.

Swift R.S. (1999) Macromolecular properties of soil humic substances: fact, fiction, and opinion. Soil Sci. 164, 790-802.

Terashima M., Fukushima M., Tanaka S. (2004) Influence of pH on the surface activity of humic acid : micelle-like aggregate formation and interfacial adsorption. Colloids Surf. A $247,77-83$.

Thieme, J. and Niemeyer, J. (1998) Interaction of colloidal soil particles, humic substances and cationic detergents studied by X-ray microscopy. Prog. Colloid Polym. Sci. 111, 193-201.

Thieme, J., Schmidt, C., Abbt-Braun G., Specht, C., Frimmel, F.H. (2002) X-ray microscopy studies of refractory organic substances. In Refractory Organic Substances in the Environment. F.H. Frimmel, G. Abbt-Braun, K.G. Heumann, B. Hock, H.-D. Lüdemann, M. Spiteller (Eds.) Wiley-VCH, Weinheim (2002) 239-248. 
Thurman, E.M., and Malcom, R.L. (1981) Preparative isolation of aquatic humic substances. Environ. Sci. Technol. 15, 463-466.

Vermeer A.W.P., van Riemsdijk W.H., Koopal L.K. (1998) Adsorption of humic acid to mineral particles. 1-Specific and electrostatic interactions. Langmuir 14(10), 2810-2819.

Viers J., Dupré B., Polvé M., Schott J., Dandurand J-L., Braun J-J. (1997) Chemical weathering in the drainage basin of a tropical watershed (Nsimi-Zoetele site, Cameroon): comparison between organic-poor and organic-rich waters. Chem. Geol. 140, 181-206.

Vilgé-Ritter, A., Rose, J., Masion, A., Bottero, J.-Y., Lainé, J.-M. (1999) Chemistry and structure of aggregates formed with Fe-salts and natural organic matter. Colloids Surf. A. Physicochem. Eng. Aspects 147, 297-308.

Wiesemann, U., Thieme, J., Guttmann, P., Niemann, B., Rudolph, D., Schmahl, G. (2000) The new scanning transmission X-ray microscope at Bessy II. In : Meyer-Ilse, W., Warwick, T., Attwood, D. (Eds) :X-ray microscopy. Proceedings 6th Intl. Conf. X-ray microscopy, Berkeley, California, August 1999. American Institute of Physics.

Wilkinson K.J., Balnois E., Leppard G.G., Buffle J. (1999) Characteristic features of the major components of freshwater colloidal organic matter revealed by transmission electron and atomic force microscopy. Colloids Surf. A Physicochem. Eng. Aspects $155,287-310$.

Wilson M.A., Barron P.F. and Gillam A.H. (1981) The structure of freshwater humic substances as revealed by 13C-NMR spectroscopy. Geochim. Cosmochim. Acta 45, 1743-1750.

Wong S., Hanna J.V., King S., Carroll T.J., Eldridge R.J., Dixon D.R., Bolto B.A., Hesse S., Abbt-Braun G., Frimmel F.H. (2002) Fractionation of natural organic matter in drinking water and characterization by $13 \mathrm{C}$ Cross-Polarization Magic-Angle Spinning NMR spectroscopy and size exclusion chromatography. Environ. Sci. Technol. 36, 3497-3503.

Zumstein, J. and Buffle, J. (1989) Circulation of pedogenic and aquagenic organic matter in an eutrophic lake. Wat. Res. 23(2), 229-239.

\section{FIGURE CAPTIONS}

Figure 1. (a): Fourier-Transformed infrared spectrum of NHA; peak assignment was carried out after Baes and Bloom, 1989. (b): ${ }^{13} \mathrm{C}$ CP-MASS NMR spectrum of NHA. 
Figure 2. Jar-tests results at $\mathrm{pH} 6$ and 8 for the 250/60 agitation sequence. (a) and (b) residual turbidity $(\bullet)$ and sediment volume (o) versus iron (III) concentration. (c) and (d) final $\mathrm{pH}\left({ }^{\bullet}\right)$ and conductivity (o) versus iron (III) concentration. The arrows on the graphs indicate the optimal coagulant concentration (OCC) and the restabilization concentration $(\mathrm{RC})$.

Figure 3. Influence of mixing conditions on the evolution of residual turbidtiy and sediment volume versus iron (III) concentration at pH 6 (a-b) and pH 8 (c-d). (o) 60/60; $(\bullet) 250 / 60$.

Figure 4. Evolution as a function of iron (III) concentration of $\mathrm{I}_{1} / \mathrm{I}_{3}$ pyrene fluorescence intensity ratio $(\bullet)$ and electrophoretic mobility (o). (a) $\mathrm{pH} 6$ and (b) $\mathrm{pH} 8$.

Figure 5. Influence of mixing conditions on the evolution of $\mathrm{I}_{1} / \mathrm{I}_{3}$ pyrene fluorescence intensity ratio and electrophoretic mobility versus iron (III) concentration. (a-b) pH 6 and (c-d) pH 8. (•) 250/60 and (o) 60/60.

Figure 6. (a) Variation of surface tension as a function of NHA concentration. (b) Surface activity of coagulated NHA versus iron (III) concentration (agitation sequence $(250 / 60) .(\bullet) \mathrm{pH} 6$ and (o) $\mathrm{pH} 8$.

Figure 7. TEM micrographs of coagulated NHA at various iron (III) concentrations and at pH 6. (a-c) 60/60; (d-f) 250/60. (a) and (d) $[\mathrm{Fe}]=2.310^{-4} \mathrm{~mol} / \mathrm{L}$; (b) and (e) $[\mathrm{Fe}]=$ $2.3810^{-4} \mathrm{~mol} / \mathrm{L}$; (c) and (f) $[\mathrm{Fe}]=4.7610^{-4} \mathrm{~mol} / \mathrm{L}$. The scale bar represents $50 \mathrm{~nm}$.

Figure 8. X-ray micrographs of (a-i) coagulated NHA and (j) iron (III) precipitate. (a) $\mathrm{pH} 2,[\mathrm{Fe}]=0 \mathrm{~mol} / \mathrm{L}$. (b-e) influence of iron (III) concentration at $\mathrm{pH} 6$; (b) and (c) [Fe] $=2.0210^{-4} \mathrm{~mol} / \mathrm{L} ;(\mathrm{d})[\mathrm{Fe}]=2.3810^{-4} \mathrm{~mol} / \mathrm{L} ;(\mathrm{e})[\mathrm{Fe}]=2.7410^{-4} \mathrm{~mol} / \mathrm{L}$. (f-i) influence of iron (III) concentration at $\mathrm{pH} 8$; (f) $[\mathrm{Fe}]=4.7610^{-4} \mathrm{~mol} / \mathrm{L} ;(\mathrm{g})[\mathrm{Fe}]=5.86 \mathrm{~mol} / \mathrm{L}$; (h) $[\mathrm{Fe}]=7.33 \mathrm{~mol} / \mathrm{L}$; (i) $[\mathrm{Fe}]=8.810^{-4} \mathrm{~mol} / \mathrm{L}$. Agitation sequence $250 / 60$. The scale bar represents $300 \mathrm{~nm}$.

Figure 9. Schematic illustration of NHA aggregation dynamics with hydrolyzed Fe coagulant species. 


\begin{tabular}{|l|c|c||c|c|}
\cline { 2 - 5 } \multicolumn{1}{c|}{} & \multicolumn{2}{c|}{ Fe/Os } & \multicolumn{2}{c|}{ Fe/Cl } \\
\hline Initial agitation $(\mathrm{rpm})$ & $\mathbf{6 0}$ & $\mathbf{2 5 0}$ & $\mathbf{6 0}$ & $\mathbf{2 5 0}$ \\
\hline$[\mathrm{Fe}]=2.310^{-4} \mathrm{~mol} / \mathrm{L}$ & 11.23 & 11.2 & 1.18 & 0.97 \\
\hline$[\mathrm{Fe}]=2.710^{-4} \mathrm{~mol} / \mathrm{L}$ & 10.44 & 17.72 & 2.28 & 1.97 \\
\hline$[\mathrm{Fe}]=4.510^{-4} \mathrm{~mol} / \mathrm{L}$ & 24.4 & 30.94 & 1.9 & 2.0 \\
\hline
\end{tabular}

Table 1: $\mathrm{Fe} / \mathrm{Os}$ and $\mathrm{Fe} / \mathrm{Cl}$ elemental ratios. Each reported value is the average of 5 EDXS analyses. 